\begin{tabular}{ccc} 
Tersedia online di: http://ejournal-balitbang.kkp.go.id/index.php/jppi & JURNAL \\
e-mail:jppi.puslitbangkan@ gmail.com & PENELTIAN \\
PERIKANAN & INDONESIA \\
JURNALPENELITIANPERIKANANINDONESIA & Volume 23 Nomor 1 Maret 2017 \\
p-ISSN: 0853-5884 & e-ISSN: 2502-6542 \\
\hline Nomor Akreditasi: 653/AU3/P2MI-LIPI/07/2015 & \\
\hline
\end{tabular}

\title{
KELIMPAHAN STOK IKAN LAYUR (Trichiurus spp.) DAN FAKTOR LINGKUNGAN YANG MEMPENGARUHINYA DI PERAIRAN PALABUHANRATU, JAWA BARAT
}

\section{FISH STOCK ABUNDANCE OF HAIRTAIL (Trichiurus spp.) AND ITS ENVIRONMENTAL INFLUENCING FACTORS IN THE WATERS OF PALABUHANRATU, WEST JAVA}

\author{
Wijopriono*1 dan Mohamad Adha Akbar ${ }^{1}$ \\ ${ }^{1}$ Peneliti pada Pusat Penelitian dan Pengembangan Perikanan, JI. Pasir Putih II, Ancol Timur Jakarta Utara, \\ 14430-Indonesia \\ Teregistrasi I tanggal: 10 Januari 2017; Diterima setelah perbaikan tanggal: 20 Maret 2017; \\ Disetujui terbit tanggal: 05 April 2017
}

\begin{abstract}
ABSTRAK
Layur telah menjadi target utama penangkapan dan dieksploitasi secara intensif di perairan Palabuhanratu menyusul permintaan ekspor yang meningkat. Kajian dilakukan untuk mengetahui kelimpahan dan faktor lingkungan yang berperan terhadap fluktuasi hasil tangkapan ikan layur. Serial data hasil tangkapan dan upaya penangkapan bulanan 2004-2015 dan serial data iklim, yaitu SST, precipitasi, Dipole Mode Index (DMI), dan Southern Oscillation Index (SOI) dalam periode waktu yang sama digunakan untuk analisis. Hasil analisis menunjukkan bahwa peningkatan signifikan upaya penangkapan yang dilakukan sampai 2007 mengakibatkan hasil tangkapan per satuan upaya (CPUE) menurun secara konstan pada tahun-tahun berikutnya. Penurunan upaya penangkapan mencapai $28,5 \%$ pada tahun 2007 tidak dapat meningkatkan CPUE secara signifikan. Berdasarkan analisis forward seletion dalam model multiregresi, diketahui bahwa faktor iklim yang berperan dalam fluktuasi hasil tangkapan adalah presipitasi serta interaksi antara DMI dan SOI._Dalam kaitan tersebut perlu dilakukan pengaturan upaya penangkapan dan memperhitungkan variabilitas iklim dalam pengelolaan sumberdaya ikan layur di Palabuhanratu.
\end{abstract}

Kata Kunci: Layur; pancing ulur; kelimpahan; variabilitas iklim; Palabuhanratu

\begin{abstract}
Hairtail has become the main fishing target and exploited intensively in the waters of Palabuhanratu, following the increase of export demand. Studies have been conducted to determine the abundance and environmental factor impact to the catches of hairtail. Serial catch and fishing effort data 2004-2015 and Serial monthly climate data, i.e., SST, precipitation, Dipole Mode Index (DMI), and the Southern Oscillation Index (SOI) of the same time period used for analysis. The results showed that the significant increase in fishing effort occurred until 2007 resulted in the catch per unit of effort (CPUE) decrease constantly in the following years. In fact, decreasing fishing effort down to $28.5 \%$ from 2007 levels may not increase CPUE significantly. Based on the forward selection analysis in the multiple regression models, it is known that the climate factor that plays a role in the fluctuation of the catch are precipitation and interaction between DMI and SOI. The results of this study suggested the need for setting the fishing effort with taking into account climate variability in management of hairtail fisheries in Palabuhanratu.
\end{abstract}

Keywords: Hairtail; hand line; abundance; climate variability; Palabuhanratu 


\section{PENDAHULUAN}

Sumberdaya ikan layur (Trichiurus spp.) merupakan spesies yang menyebar di paparan kontinen dan laut dangkal, banyak tertangkap di perairan hangat tropik maupun sub-tropik. Ikan ini umumnya banyak ditemukan di dasar berlumpur perairan pantai yang dangkal, bergerak di permukaan pada malam hari dan sering menembus muara (Randall, 1995; Nakamura \& Parin, 1993). Di perairan Indonesia terdapat 6 jenis ikan layur yaitu Trichiurus haumela. T. savala, T. lepturus, T. muticus, $T$. glossodon, T. Auriga dan menyebar di perairan osenanik termasuk Palabuhanratu perairan Samudera Hindia (Nontji, 1987; Badrudin \& Wudianto, 2004).

Eksploitasi sumberdaya ikan layur secara tradisional di Palabuhanratu telah berlangsung sejak lama.Akibat permintaan ekspor yang terus meningkat,menjadikan sumberdaya ikan layur (Trichiurus spp.) menjadi target utama penangkapan.Usaha penangkapan ikan ini terus berkembang dan menjadi salah satu andalan pendapatan dari sub sektor perikanan di wilayah ini. Pada tahun 2015, produksi total hasil tangkapan layur di Palabuhanratu tercatat 90,30 ton dengan nilai mencapai 2,19 milyar rupiah atau tiga kali lipat dibanding tahun 2004 (PPN Palabuhanratu, 2015).

Jenis alat tangkap utama untuk menangkap layur adalah pancing ulur, sementara alat tangkap lain seperti bagan, pukat cincin, jaring insang juga mampu menangkap layur namun sebagai hasil tangkapan sampingan. Kapal yang digunakan umumnya berukuran $\leq 5$ GT dengan mesin tempel (outboard) sebagai tenaga penggerak kapal berkekuatan 5,5-15 PK, serta awak kapal 2-3 orang. Operasi penangkapan dilakukan di dalam dan sekitar teluk Palabuhanratu (Anggawangsa et al., 2009).

Beberapa penelitian telah dilakukan untuk kepentingan pengelolaan, termasuk tingkat pemanfaatan layur di Palabuhanratu(Astuti, 2008; Harjanti et al., 2012), namun informasi yang tersedia tentang trend kelimpahan, fluktuasi tangkapan dan faktor yang mempengaruhinya, khususnya lingkungan, belum banyak tersedia. Beberapa tahun terakhir ini penelitian difokuskan tentang bagaimana kelimpahan layur dipengaruhi variabilitas iklim sehingga pengetahuan ini akan berguna bagi pengelolaan sumber daya ikan dalam kaitannya dengan upaya adaptasi terhadap dampak perubahan iklim.
Tulisan ini menganalisis kelimpahan sumberdaya layur berdasarkan hasil tangkapan pancing ulur di Palabuhanratu, meliputi fluktuasi dan pergeseran kelimpahan serta mengidentifikasi variabel iklim yang mempengaruhinya.

\section{BAHAN DAN METODE Pengumpulan Data}

Pengumpulan data dilaksanakan Maret dan Nopember 2015 melalui survei di pusat pendaratan ikan PPN Palabuhanratu, Jawa Barat. Data hasil tangkapan bulanan dari tahun 2004-2015 diperoleh dari catatan pendaratan kapal-kapal komersial penangkap ikan.Data historis hasil tangkapan layur, frekuensi kapal melaut (trip penangkapan), serta daerah tangkapan selama kurun waktu 2004-2015 digunakan sebagai dasar kajian. Serial data Dipole Mode Index (DMI), Sea Surface Temperature (SST) dan Presipitasi/curah hujan dari JAMSTEC (http:// www.jamstec.go.jp)dan serial data Southern Oscillation Index (SOI)dari Bureau of Meteorology, Australia (http://www.bom.gov.au) periode 2004-2015 digunakan untuk analisis pengaruh faktor lingkungan.

\section{Analisis Data}

Perubahan temporal CPUE digunakan sebagai dasar untuk mengukur fluktuasi kelimpahan relatif stok sumberdaya layur, dengan asumsi bahwa kemampuan tangkap kapal tidak berubah (konstan) untuk semua armada tangkap (Beverton \& Parrish, 1956; Gulland, 1956; Robson, 1966). Nilai CPUE dihitung dari hasil tangkapan total layur dibagi jumlah trip kapal, dimana durasi trip pancing ulur adalah harian (one day fishing).

Tingkat kelimpahan ditetapkan berdasarkan indeks persen rata-rata CPUE bulanan selama periode 20042015 dan diestimasi menggunakan analisis runtun waktu (Times Series Analysis) (Spiegel, 1961):

$\mathrm{IK}_{i}=\frac{1}{t} \sum_{i=1}^{t} U_{p}$

dimana:

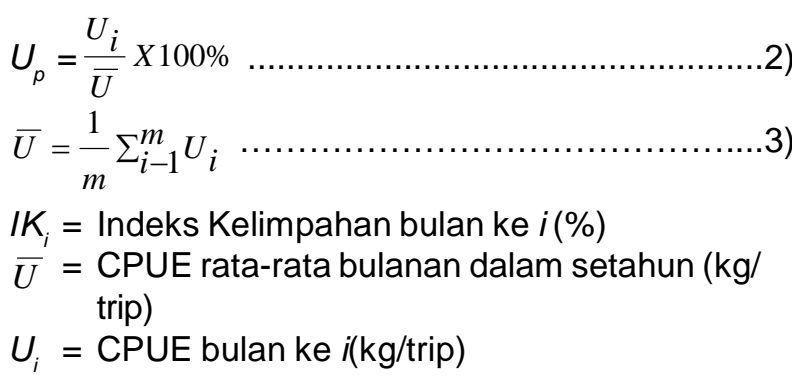


$m$ = jumlah bulan dalam setahun

$t=$ jumlah tahun data

Untuk menentukan variabel lingkungan yang paling berkorelasi dengan variasi temporal hasil tangkapan, digunakan metode general linear model (GLM):

$y=\beta_{0}+\beta_{1} X \beta_{1}+\beta_{2} X \beta_{2}+\ldots . .+\beta_{m} X \beta_{m}+\varepsilon$

$y=$ Variabel terikat (Hasil Tangkapan)

$x_{m}=$ Variabel bebas $/$ prediktor

$\beta_{0}=$ Konstanta

$\beta_{m}=$ Koefisien regresi ke $-m$

$\varepsilon=$ Residual

Variable-variabel prediktor meliputi CPUE, Trip, SST, presipitasi, DMI, dan SOI.Seleksi variabelvariabel yang berpengaruh terhadap fluktuasi hasil tangkapan dilakukan prosedur forward selection.

\section{HASIL DAN BAHASAN Hasil}

Pancing ulur di Palabuhanratu setidaknya menangkap tiga spesies layur, yaitu Trichiurus haumela, T. lepturus, Lepturacanthus savala dan Gempylus serpens. Hasil tangkapan periode 2004-2015 berfluktuasi, dengan rata-rata 142,04 ton per tahun. Hasil tangkapan layur dari pancing ulur meningkat sejak 2004 dan mencapai produksi tertinggi sebesar 247 ton pada 2007 atau meningkat $170 \%$ dibanding 2004. Namun demikian, pada tiga tahun berikutnya hasil tangkapan menunjukkan trend yang terus menurun dan mencapai jumlah tangkapan terendah pada 2010, yaitu 36,73 ton. Catatan pendaratan ikan menunjukkan adanya peningkatan kembali hasil tangkapan sampai 2012, namun kembali menurun pada tahun-tahun berikutnya. Pada 2015, hasil tangkapan tercatat 90,30 ton, hanya 37\% dibanding 2007 (Gambar 1).

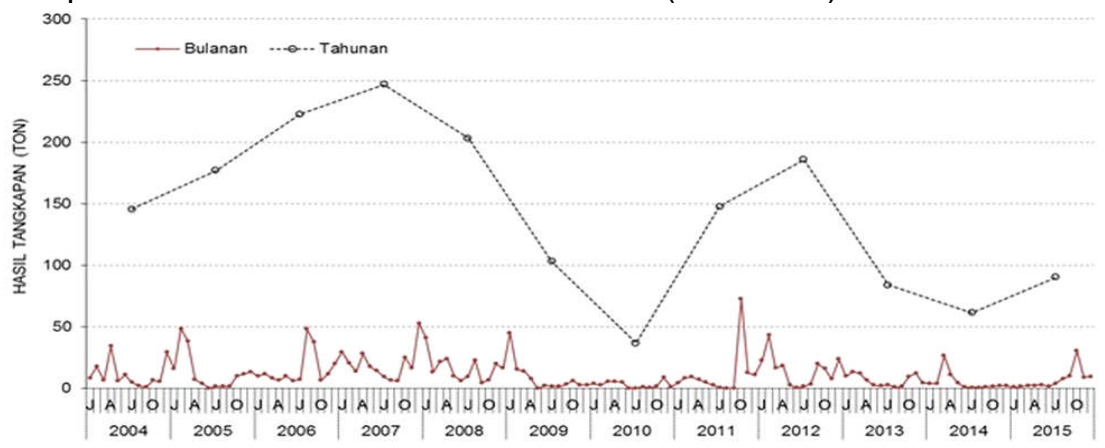

Gambar 1. Hasil tangkapan bulanan dan tahunan layur (Trichiurus spp) yang didaratkan di Palabuhanratu, Jawa Barat pada 2004-2015.

Figure 1. Monthly and annual catches of hairtail landed at Palabuhanratu, West Java in 2004-2015.

Jumlah penangkapan (trip) dengan pancing ulur yang menangkap layur berfluktuasi sepanjang periode 2004-2015 (Gambar 2). Upaya penangkapan meningkat tajam sejak 2005 sampai 2007, dari 3.486 trip pada 2005 meningkat lebih dari empat kali lipat menjadi 14.826 trip pada 2007. Peningkatan upaya ini menghasilkan kenaikan produksi sebesar 247 ton
(Gambar 1) meningkat $140 \%$ dibanding 2005. Disisi lain, upaya yang tinggi menyebabkan penurunan hasil tangkap per unit upaya (CPUE), dari $64,41 \mathrm{~kg} /$ trip pada 2005 menjadi 16,96 kg/trip pada 2007. Penurunan upaya penangkapan sampai $28,5 \%$ pada periode tiga tahun berikutnya (2010), dan sampai 2015 upaya tersebut cenderung terus menurun.

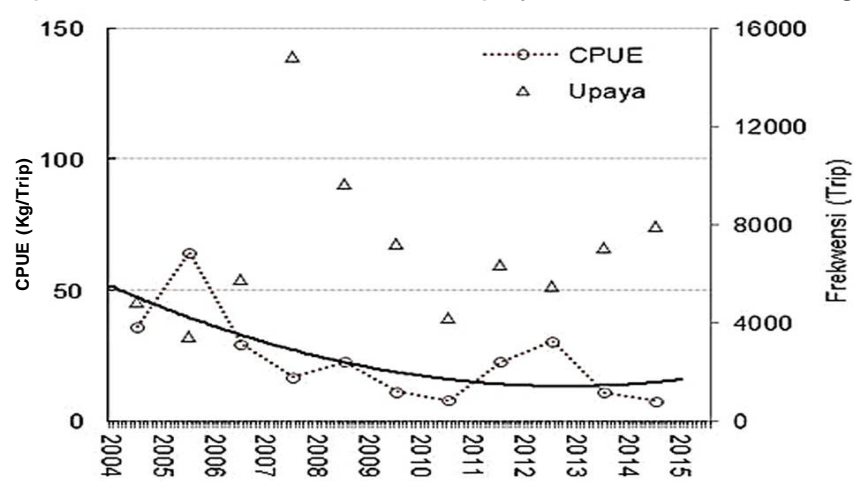

Gambar 2. Upaya penangkapan dan hasil tangkapan per satuan upaya (CPUE) layur pada armada pancing ulur pada 2004-2015.

Figure 2. Fishing effort and catch per unit effort (CPUE) of hairtail caught by hand line fleet in 2004-2015. 
Hasil tangkapan bulanan perikanan layur pada periode 2004-2015 menunjukkan fluktuasi kelimpahan musiman yang relatif konstan dari tahun ke tahun (Gambar 3). Hasil analisis menunjukkan bahwa kelimpahan yang relatif tinggi terjadi pada Oktober sampai dengan Maret dengan dua puncak, Oktober dan Maret. Kelimpahan yang relatif rendah terjadi sepanjang April sampai September dengan kelimpahan terendah terjadi pada Juni. Kelimpahan tertinggi terjadi pada 2014, mencapai $300 \%$ dari ratarata tahunan pada Maret dan mendekati $200 \%$ dari rata-rata tahunan pada Oktober. Sebaliknya, anomali terjadi pada tahun 2015 dimana kelimpahan tinggi terjadi dalam rentang waktu yang lebih pendek yaitu mulai pertengahan Agustus sampai Desember, dengan puncak Sepember.

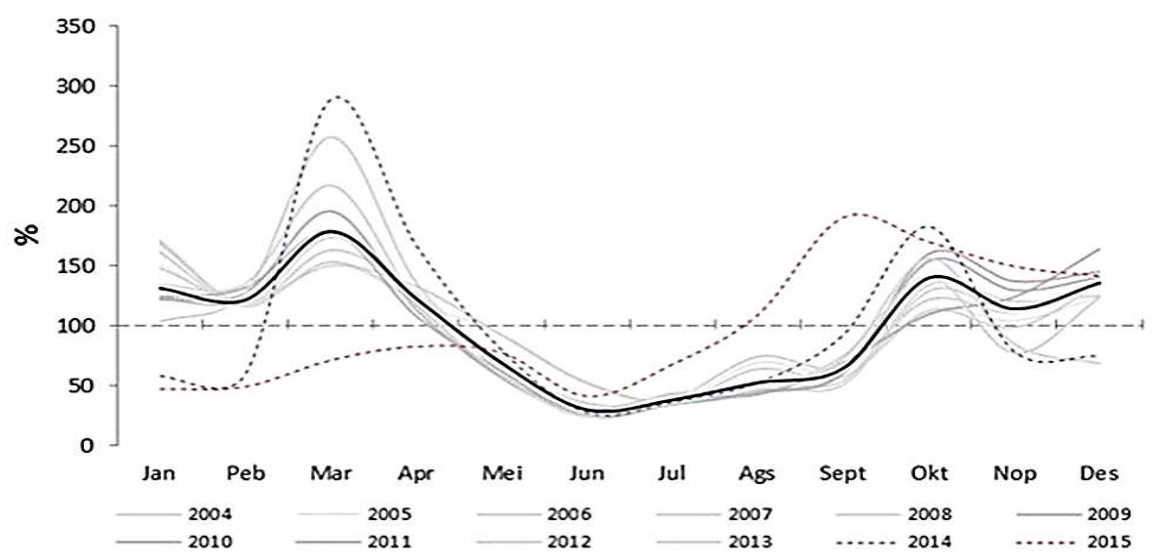

Gambar 3. Fluktuasi dan pergeseran musim kelimpahan layur di perairan Palabuhanratu.

Figure 3. Fluctuation and seasonal shifting of hairtail abundance in the waters of Palabuhabratu.

Pergeseran musim penangkapan dan fluktuasi hasil tangkapan yang terjadi pada perikanan ini mengindikasikan adanya pengaruh variabilitas iklim. Untuk mengetahui pengaruh tersebut dilakukan pengujian terhadap beberapa variabel iklim yang diperkirakan berpengaruh terhadap lingkungan oseanografi. Variabilitas iklim selama periode pengamatan, 2004-2015, adalah seperti disajikan dalam Tabel 1.

Tabel 1. Rata-rata parameter iklim di perairan Palabuhanratu periode 2004-2015

Table1. Climate parameter average in the waters of Palabuhanratu during 2004-2015

\begin{tabular}{lcccc}
\hline \multicolumn{1}{c}{ Variabel } & Unit & Maksimum & Minimum & Rata $^{2} \pm$ Std deviasi \\
\hline Suhu Permukaan Laut/SST & ${ }^{0} \mathrm{C}$ & 30.86 & 28.19 & $29.72 \pm 0.62$ \\
Curah hujan/Presipitasi & $\mathrm{mm} /$ bulan & 342.70 & 62.95 & $225.84 \pm 63.61$ \\
DMl & - & 0.87 & -0.71 & $0.16 \pm 0.28$ \\
SOI & - & 27.10 & -28.60 & $1.06 \pm 10.86$ \\
\hline
\end{tabular}

Hasil seleksi melalui prosedur foreward stepwise adalah presipitasi dan interaksi antara DMI dan SOI, regression menunjukkan bahwa variabel iklim yang sedangkan untuk variabel perikanan adalah CPUE dan berperan terhadap variabilitas hasil tangkapan layur jumlah trip penangkapan (Tabel 2).

Tabel2. Ringkasan statistik foreward stepwise regression dengan variabel respon log. hasil tangkapan pada level $p<0,05, \mathrm{~N}=144$

Table 2. Summary statistics of foreward stepwise regression with respon variable log. catch at plevel < $0,05, N=144$

\begin{tabular}{lccccc}
\hline \hline Variabel & Konstanta & $\boldsymbol{\beta}$ & Std Error & VIF & $\mathbf{R}^{2}$ \\
\hline Trip & 2,443 & & & & 0,531 \\
CPUE & & 0,578 & 0,000 & 1,063 & \\
Presipitasi & & 0,478 & 0,001 & 1,049 & \\
DMI*SOI & & 0,224 & 0,001 & 1,173 & \\
\hline
\end{tabular}

Ket.: $\quad$ - DMI*SOI : interaksi antara DMI dan SOI

$$
\text { - VIF : variance inflation factor }
$$

Dua variabel perikanan dan dua variabel iklim dapat menjelaskan $53,1 \%$ variasi dalam model. Sedangkan
SST, SOI dan DMI secara individual tidak memenuhi kriteria seleksipada level $p<0,05$ (Tabel2). 
DMI dan SOI merupakan indikator-indikator iklim yang mempengaruhi kondisi oseanografi di Samudera Hindia dan Pasifik, yang secara geografis saling berhubungan. Kedua variable prediktor tersebut saling terkait dengan variabel SST, dan dalam model ini interaksi variabel DMI dan SOI lebih dapat menjelaskan pengaruhnya terhadap variasi kelimpahan layur.
Gambar 4 menunjukkan bahwa pada Awal 2005 dan Agustus-Oktober 2006 terjadi pergerakan interaksi SOI*DMI yang kuat, disusul pada 2010-2011, dan interaksi yang sangat kuat terjadi pada AgustusOktober 2015. Terlihat bahwa pada rentang waktu tersebut CPUE menunjukkan pergerakan yang berlawanan.

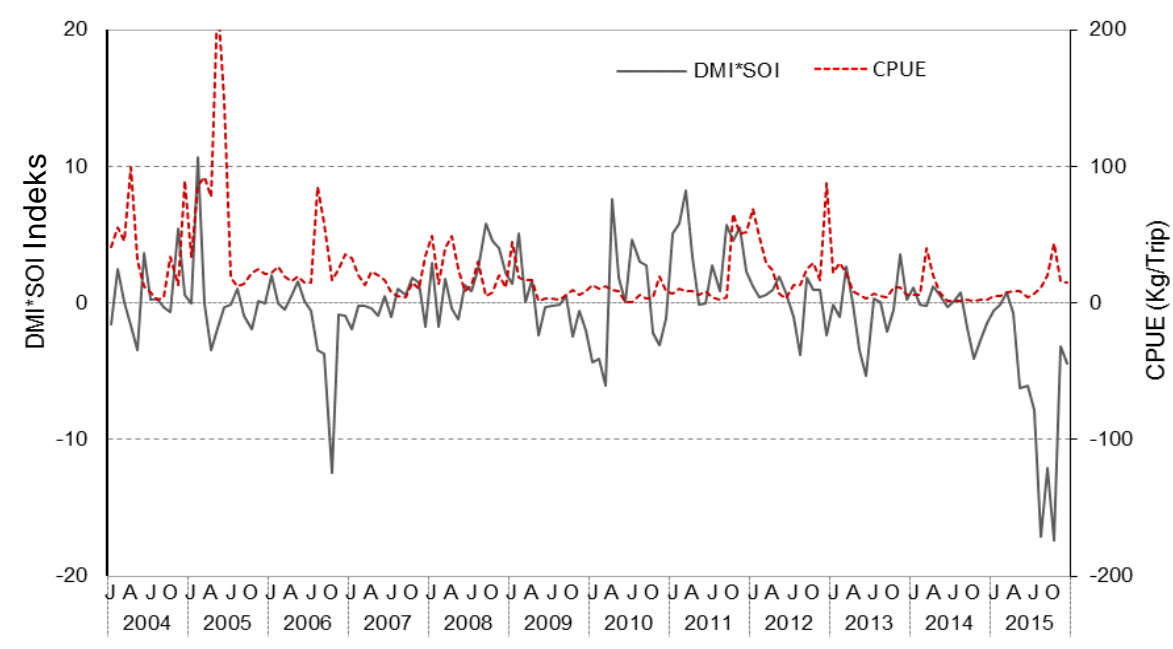

Gambar 4. Plot interaksi DMI dan SOI terhadap fluktuasi CPUE layur.

Figure 4. Plot of DMI and SOI interaction versus fluctuation of hairtail.

Gambar 5. Menunjukkan bahwa presipitasi di Palabuhanratu berfluktuasi sepanjang 2004-2015 dan berhubungan positif dengan CPUE. Meskipun demikian, kondisi berlawanan terjadi pada periode
2010-2011 dan paruh akhir 2015, pada periode dimana angka CPUE paling rendah seperti diperlihatkan pada Gambar 2.

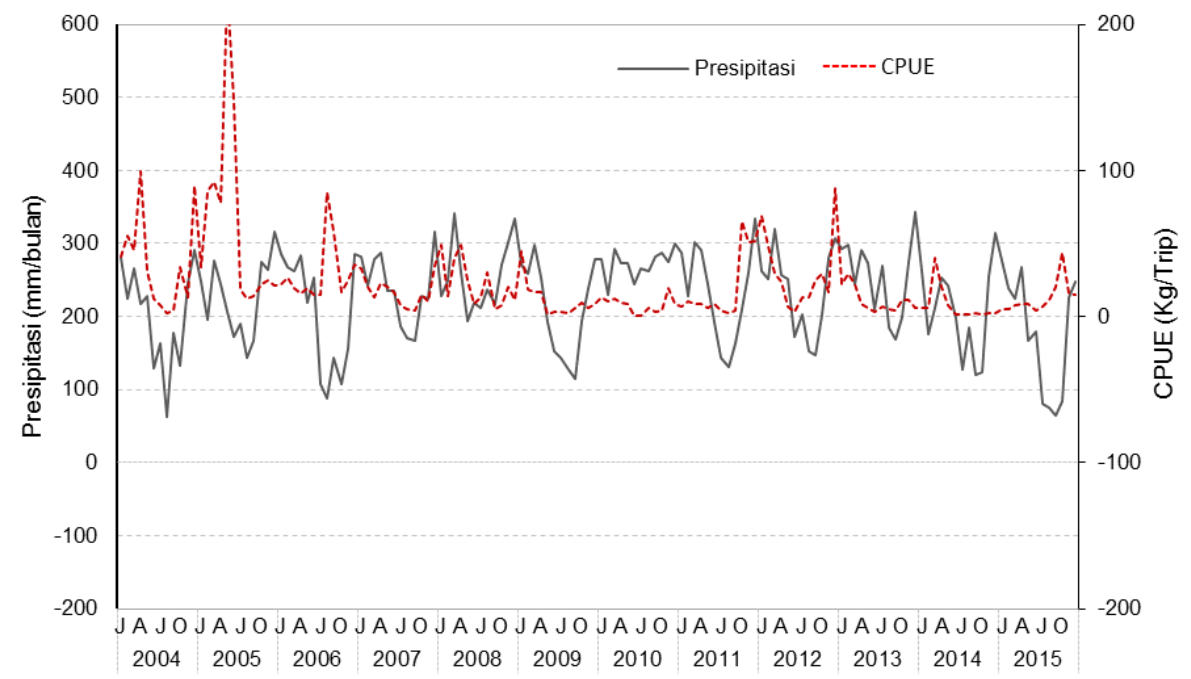

Gambar 5. Plot presipitasi terhadap fluktuasi CPUE layur.

Figure 5. Plot of precipitation versus fluctuation of hairtail CPUE. 


\section{Bahasan}

Kelimpahan stok layur yang ditunjukkan dari nilai CPUE bersifat musiman, kelimpahan tinggi terjadi pada Oktober sampai dengan Maret, dengan dua puncak, oktober dan Maret. Kelimpahan rendah terjadi sepanjang April sampai September, dengan kelimpahan terendah terjadi pada Juni. Kwok \& Ni (1999) menemukan bahwa periode pemijahan Trichiurus lepturus berlangsung pada Maret sampai Juni, sementara menurut Kim et al. (2005) berlangsung pada Mei sampai Agustus. Sejalan dengan itu, hasil penelitian terhadap pola pergerakan migrasi layur ditemukan bahwa stok layur beragregasi pada Maret, dispersi antara April dan September, dan beragregasi kembali pada Oktober dan Desember (Cheng et al., 2013).

Hasil analisis menunjukkan bahwa salah satu variabel iklim yang berpengaruh terhadap hasil tangkapan layur adalah curah hujan/presipitasi. Presipitasi dari daratan menginduksi limpasan sungai yang memberikan masukan nutrisi ke ekosistem pesisir. Pengayaan nutrisi memiliki efek positif pada produksi ikan secara keseluruhan (Qiu et al., 2010; Hoguane \& Armando, 2015). Hal ini diverifikasi oleh korelasi positif antara jumlah tangkapan dan presipitasi di perairan Palabuhanratu (Tabel 2 dan Gambar 4).

Presipitasi yang tinggi dapat mengakibatkan pengenceran dan menurunkan kadar salinitas di area pantai. Hasil-hasil penelitian membuktikan bahwa hasil tangkapan layur melimpah pada periode dimana salinitas perairan rendah dan sebaliknya (Kim \& Rho, 1998; Ansari et al., 2003; Kantoussan et al., 2012). Lebih lanjut, Kim et al. (2005) menemukan larva layur dengan densitas yang tinggi di area bersalinitas rendah selepas periode musim hujan di perairan pantai utara Laut China Timur.

DMI dan SOI menunjukkan indeks osilasi tekanan udara antara hangat (warm) dan dingin (cold) masingmasing di Samudera Hindia dan Pasifik. Osilasi tekanan udara ini berinteraksi dengan laut membentuk pola iklim yang mempengaruhi kondisi oseanografi atau ekosistem sekitarnya (Chavez et al., 2003). Terkait dengan hal ini, beberapa hasil penelitian oseanografi di Samudera Hindia selatan Jawa menunjukkan kuatnya pengaruh fenomena interaksi tersebut (Hermawan \& Komalaningsih, 2008; Kunarso et al., 2011)

\section{KESIMPULAN}

Hasil tangkapan layur berfluktuasi secara musiman dengan kelimpahan tertinggi terjadi sepanjang
Oktober dan Maret dan kelimpahan terendah berlangsung sepanjang April sampai dengan September. Musim puncak tertinggi terjadi pada Oktober dan Maret, sementara terendah pada Juni. Kelimpahan sumberdaya layur menunjukkan kecenderungan yang terus menurun akibat intensitas penangkapan yang tinggi. Pola fluktuasi hasil tangkapan bervariasi karena pengaruh faktor lingkungan, khususnya presipitasi serta interaksi antara DMI dan SOI. Dengan demikian perlu dilakukan pengaturan upaya penangkapan dengan memperhitungkan faktor lingkungan dalam pengelolaan sumberdaya layur di Palabuhanratu.

\section{PERSANTUNAN}

Tulisan ini merupakan bagian dari kegiatan enumerasi pada Pusat Penelitian dan Pengembangan Perikanan 2015-2016. Ucapan terima kasih disampaikan kepada Administrator Pelabuhan Perikanan Nusantara (PPN) dan enumerator di Palabuhanratu yang telah membantu dalam pengumpulan data.

\section{DAFTAR PUSTAKA}

Anggawangsa, R. F., Murdiyanto, B., \& Wudianto. (2009). Pengaruh penggunaan mata pancing ganda pada rawai tegak terhadap hasil tangkapan layur. Bawal. 2(6), 323-330.

Ansari, Z. A., Sreepada, R. A., Dalal, S. G., Ingole, B. S., \& Chatterji, A. (2003). Environmental influences on the trawl catches in a bayestuarinesystem of Goa, west coast of India. Estuarine, Coastal and Shelf Science. 56, 503-515.

Astuti, W. (2008). Pengelolaan dan pemanfaatan sumberdaya ikan layur di perairan Palabuhanratu, Sukabumi, Jawa Barat. Skripsi. Departemen Pemanfaatan Sumberdaya Perikanan, Fakultas Perikanan Dan IImu Kelautan Institut Pertanian, Bogor. 88 hal.

Badrudin \& Wudianto. (2004). Biologi, habitat, dan sebaran ikan layur serta beberapa aspek perikanannya (p. 13). Diseminarkan pada Workshop Rencana Pengelolaan Perikanan Layur.Co Fish Project.

Beverton, R. J. H., \& Parrish, B. B. (1956). Commercial statistics in ûsh population studies. Rapp. Proc. Verb. Reun. Cons. Int. Explor. Mer. 140, 58-66.

Chavez, F. P., Ryan, J., Lluch-Cota, S. E., \& Niquen, 
M. (2003). From anchovies to sardines and back: Multidecadal change in the Pacific Ocean. Science 299, 217-221.

Cheng, C. H., Kawasaki, T., Chiang, K. P., \& Ho, C.H., (2013). Alternative assessment methodsapplied to the hairtail(Trichiurus lepturus) stockin the Aru Sea as an example. J. Mar. Sci. and Tech., 21 (Suppl.), 223-229

Gulland, J. A. (1956). On the fishing effort in English demersal fisheries. Fish. Invest. London 20 (Series 2), 1-41.

Harjanti, R., Wibowo, P., \& Hapsari, T.D. (2012). Analisis musim penangkapan dan tingkat pemanfaatan ikan layur (Trichiurus sp) di Perairan Palabuhanratu, Sukabumi, Jawa Barat. J. Fish Res Util. Manag. and Tech. 1(1) 2012, 55-66

Hermawan, E., \& Komalaningsih, K. (2008). Karakteristik Indian Ocean Dipole Mode di Samudera Hindia hubungannya dengan perilaku curah hujan di kawasan sumatera barat berbasis analisis mother wavelet.J. Sains Dirgantara. 5 (2), 109-129.

Hoguane, A. M., \& Armando, E. V. (2015). The influence of the river runoff in the artisanal fisheries catchesin tropical coastal waters - The case of the Zambezi River and thefisheries catches in the northern Sofala Bank, Mozambique. Journal of Integrated Coastal Zone Management, 15(4),443451.

Kantoussan, J., Ecoutin, J. M., Simier, M., de Morais, L. T., \& Raymond Lae, R. (2012). Effects of salinity on fish assemblage structure: An evaluation based on taxonomicand functional approaches in the Casamance estuary (Senegal, West Africa) Estuarine. Coastal and Shelf Science, 113,152162.

Kim, J-Y., Kang, Y-S., Hyun-ju Oh, H-J.,Suh, Y-S., \& Hwang, J-D. (2005). Spatial distribution of early life stages of anchovy(Engraulis japonicus) and hairtail (Trichiurus lepturus) andtheir relationship with oceanographic features of theEast China Sea during the 1997-1998 El Nino Event. Estuarine, Coastal and Shelf Science, 63,13-21.

Kim, S-H., \& Rho, H-K. (1998). A Study on the As- sembling Mechanism of the Hairtail, Trichiurus Lepturus, at the Fishing Grounds of the Cheju Strait. Bulletin of the Korean society of Fisheries Technology, 34(2), 1-10.

Kunarso, Hadi, S., Ningsih, N. S., Mulyono., \& Baskoro, S. (2011). Variabilitas suhu dan klorofila di daerah upwelling pada variasi kejadian ENSO dan IOD di perairan selatan Jawa sampai Timor. IImu Kelautan. 16 (3), 171-180.

Kwok, Y., \& Ni, I. H. (1999). Reproduction of cutlassfishes Trichiurus spp. Fromthe South China Sea. Mar. Ecol. Prog. Ser, 176, 39-47.

Nakamura, I., \& Parin, N. V. (1993). FAO species catalogue. Vol. 15.Snake mackerels and cutlass fishes of the world (Families Gempylidae and Trichiuridae). An annotated andillustrated catalogue of the snake mackerels, shocks, escolars, gemfishes, sack fishes,domine, oilfish, cutlassfishes, scabbardfishes, hair- tails, and frostfishes known todate. Fisheries Synopsis No. 125, Vol. 15. FAO, Rome, pp. 136.

Nontji, A. 1987. Laut Nusantara (p. 368). Penerbit Djambatan. Jakarta.

PPN Palabuhanratu, 2004-2015. Laporan Tahunan Statistik Pelabuhan Perikanan Nusantara Perikanan Nusantara Palabuhanratu 2004-2015. Jawa Barat: Kementerian Kelautan dan Perikanan.

Qiu, Y., Lin, Z., \& Wang, Y.(2010). Responses of fish production to fishing and climate variability in the northern South China Sea. Progress in Oceanography, 85, 197-212.

Randall, J. E. (1995). Coastal fishes of Oman (p. 439). Crawford House Publishing Pty Ltd., Bathurst,New South Wales, Australia.

Robson, D. S. (1966). Estimation of relative ûshing power of individual ships. ICNAF Res. Bull. 2, 514.

Spiegel, M. R. (1961). Theory and Problems of Statistics (p. 359). New York: Schaum Publ. Co.

Stenseth, N., Ottersen, G., Hurrell, W., Mysterud, A., 
Lima, M., Chan, K., Yoccoz, N., \& Ådlandsvik, B. (2003). Studying climate effects on ecology through the use of climateindices: the North At- lantic Oscillation, El Niño Southern Oscillation and beyond. Proc. R. Soc. Lond. 270: 1-10. 